\title{
Carotid Sinus Hypersensibility: A Concept on the Way ${ }^{*}$
}

\author{
Alfonso Lagi \\ Ospedale Santa Maria Nuova, Firenze, Italia. \\ Email: alfonso.lagi1@tin.it \\ Received November $25^{\text {th }}$, 2012; revised December $27^{\text {th }}$, 2012; accepted January $11^{\text {th }}, 2013$
}

\begin{abstract}
This review examines the pathogenesis of Carotid Sinus Hypersensitivity (CSH) by describing the different hypotheses that exist in literature. One hypothesis is that CSH is not a disease of the heart but of the central and/or peripheral nervous system where the heart is the victim. CSH is associated with cognitive disturbance, vasovagal syncope and orthostatic hypotension. Another hypothesis is that the CSH is considered a syndrome or a symptom associated with different diseases so as to require a diagnostic framework. This Hypothesis is the basis of frequent recurrences that are associated with the pacemaker implant therapy only.
\end{abstract}

Keywords: Syncope; Autonomic Nervous System; Pacing; Physiology

\section{Introduction}

Carotid sinus hypersensitivity (CSH) becomes a disease when it becomes responsible of falls and syncope. In this case the diction carotid sinus syndrome (CSS) is preferred. These are the cases handled, whether cardio-inhibitory type or even if mixed, with implantation of pacemaker (PM). In contrast with this therapeutic progress, the pathophysiology of the syndrome remains poorly understood. Indeed, the question arises whether the answer in bradycardia and hypotension that you get with the massage of the carotid sinus (MSC) is really just a physiological response that grows up to cause symptoms when the age progresses. And this occurs mainly in males.

\section{CHS and Heart}

In the collective idea, the $\mathrm{CSH}$ is considered a heart disease. Post hoc propter hoc: it is obvious if the remedy is just that, the cause is related. The CSS has been considered symptom of sino-atrial disease [1,2]. Indeed, patients with CSS usually have normal sinus node function [3], nor is there a clear demonstration that the heart is patient when the subject is symptomatic carrier (CSS) or asymptomatic to CSH. The heart is the victim of a spiteful neurologic reflex which sometime shows a prevalent vasodepressor response [4]. This does not concern the sinus node and suggests that the abnormality lies in some place of the reflex arc or at the level of the carotid sinus receptors [5]. The asymmetrical response between left

\footnotetext{
*Any conflict of interest declared.
}

and right MSC gives the concept support of a pathological reflex arc rather than of a target organ.

The CSH has a population over 65 years from $14 \%$ to $39 \%$ [6], CSS hacks in $16 \%$ of males and $8 \%$ of females [7]. It is without any doubt that, at the same old age, the subjects suffering from $\mathrm{CSH}$ and who are symptomatic for CSS are minority. This puts them outside the "normal" and proposes a strong evidence in favour of specific pathology.

\section{CHS and Brain}

Patients with cognitive diseases, particularly with dementia, show strong association with the CSH, particularly in dementia with lewy bodies (DLB) [8]. This observation does not appear to be significantly related to ageing. Other morbid conditions such as Alzheimer's disease (AD) do not have the same link. A degenerative hypothesis tries to unify the Central Nervous System degenerative diseases (AD, DLB and Parkinson's disease ) when are associated with CSH. The degeneration of medullary autonomic nuclei which regulate baroreflex responses for accumulation of material (i.e. hyperphosphorylate-tau protein or fibrillar amyloid-beta) [9] allows to think of a progressive involvement of cognitive, motor and autonomic activities [8].

\section{CHS and Peripheral Nervous System}

So, if the therapeutic problem finds a solution replacing the electrical activity of the heart does not mean that this is the only form of therapy.

The stripping of adventitia from the common carotid 
artery, the bifurcation, and for about $1 \mathrm{~cm}$ up both the external and internal carotid arteries was used to treat CSS with excellent results due to the fact that $85 \%$ of patients remained asymptomatic. The experience is limited to two surgical groups and a few cases [10-12]. The more recent review [13] refers to 130 procedures. The data is very significant: it is demonstrated that patients remain asymptomatic and this is index that alternative therapeutic answers there are. May be they are more complex and more difficult to implement, less documented, but certainly no less reliable, than PM implantation [10-13]. However, what we need to discuss here is the pathophysiological significance of the surgical intervention. Solving the problem of CSH and CSS modifying the reflex arc and acting on peripheral receptor, it provides an indication on the beginning site of the disease. It indicates that the event is not in the pathological effector organ, i.e. the heart. And that is enough to move the pathophysiological interest on the peripheral or central nervous system.

It is in this perspective that we can read some cases properly investigated who proposed a relationship between CSH and the complete or partial denervation of the sternocleidomastoid muscle $[14,15]$ associated with a defect of proprioceptive information flow. The central nervous system, without any information about the contractile state of the muscles, interprets any information coming from the carotid sinus receptors only as an abrupt increase in blood pressure and reacts by a dramatic decrease in heart rate and/or blood pressure. This issue is not yet sufficiently supported by adequate survey, although numerically sporadic observations, relating to cervical pathology that has involved the carotid sinus, may intrude on this line of thought. [16-18].

\section{CHS and Dysautonomia}

Finally an association is reported between CSH and cardiovascular dysautonomia, witnessed by the changed baroreflex $[19,20]$ and by the presence of orthostatic hypotension $(\mathrm{OH})$. The matter of this link comes from patients studied with both MSC and tilt test. Carotid sinus hypersensitivity and $\mathrm{OH}$ are common conditions affecting patients with syncope and falls which are likely to co-exist in such individuals. The differences in haemodynamic response patterns to active stand and HUT in CSH subjects could be the result of an age-associated delay in sympathetic responses [21]. Indeed, the simultaneous presence of $\mathrm{CSH}$ and $\mathrm{OH}$ is present in $55 \%$ of patients selected for syncope in a single study (SYSTEMA I-Malmo) [22] but there are not still enough data to say that these subjects have a pathology of autonomic nervous system or that do not have a random association between the two diseases. In a population of over 60s, collected in different cases and selected for syncope and falls, the CSH was present between $12.8 \%$ and $45 \%$ and $\mathrm{OH}$ between $24 \%$ and $32 \%$ of subjects [2326]. Their association did not appear strong as it was agerelated [23,27].

Orthostatic hypotension and CSH are both found frequently in older people being investigated for falls. Older age, male sex and symptoms of syncope are all associated with a higher likelihood of a diagnosis of either $\mathrm{CSH}$ or $\mathrm{OH}$. Unlike $\mathrm{OH}$, the prevalence of $\mathrm{CSH}$ varies widely between different study populations, possibly due to demographic differences.

In conclusion, it can certainly affirm that some patients, males and elderly, suffer simultaneously or more frequently in the progression of either diseases associated with CSH: $\mathrm{OH}$ and dementia. The absence of true associations between $\mathrm{OH}$ and dementia with $\mathrm{CSH}$ does not support the theory of an association leading to a common mechanism between the three conditions [21].

This can certainly mean that these three diseases have a high incidence in male elder but because those who are affected are a minority you can't exclude that a progressively degenerative disease is working in these patients up to affect different organs and systems.

The data is not demonstrated but is a fascinating hypothesis on which to build longitudinal studies.

\section{REFERENCES}

[1] A. Leatham, “Carotid Sinus Syncope,” British Heart Journal, Vol. 47, No. 5, 1982, pp. 409-410. doi:10.1136/hrt.47.5.409

[2] L. Gould, C. V. Reddy, W. H. Becker, K. C. Oh and S. G. Kim, "Usefulness of Carotid Sinus Pressure in Detecting the Sick Sinus Syndrome,” Journal of Electrocardiology, Vol. 11, No. 3, 1978, pp. 261-268. doi:10.1016/S0022-0736(78)80126-5

[3] C. A. Morley, W. M. Hudson, E. J. Perrins and R. Sutton, "Is There a Difference between Sick Sinus Syndrome and Carotid Sinus Syndrome?” British Heart Journal, Vol. 49, 1983, pp. 620-621.

[4] S. McIntosh, J. Lawson and R. A. Kenny, "Clinical Characteristics of Vasodepressor Cardio Inhibitory and Mixed Carotid Sinus Syndrome in the Elderly," American Journal of Medicine, Vol. 95, No. 2, 1993, pp. 203-208. doi:10.1016/0002-9343(93)90261-M

[5] S. Weiss and J. Baker, "The Carotid Sinus Reflex in Health and Disease: Its Role in the Causation of Fainting and Convulsions," Medicine, Vol. 12, No. 3, 1933, pp. 297-354. doi:10.1097/00005792-193309000-00003

[6] N. van der Velde, A. H. van den Meiracker, H. A. Pols, B. H. Stricker and T. J. van der Cammen, "Withdrawal of Fall-Risk-Increasing Drugs in Older Persons: Effect on Tilt-Table Test Outcomes," Journal of the American Geriatrics Society, Vol. 55, No. 5, 2007, pp. 734-739. doi:10.1111/j.1532-5415.2007.01137.x

[7] N. P. Kumar, A. Thomas, P. Mudd, R. O. Morris and T. 
Masud, "The Usefulness of Carotid Sinus Massage in Different Patient Groups,” Age Ageing, Vol. 32, No. 6, 2003, pp. 666-669. doi:10.1093/ageing/afg114

[8] M. Oinas, A. Paetau, L. Myllykangas, I. L. Notkola, H. Kalimo and T. Polvikoski, " $\alpha$-Synuclein Pathology in the Spinal Cord Autonomic Nuclei Associates with $\alpha$-Synuclein Pathology in the Brain: A Population-Based Vantaa 85+ study," Acta Neuropathologica, Vol. 119, No. 6, 2010, pp. 715-722. doi:10.1007/s00401-009-0629-6

[9] V. M. Miller, R. A. Kenny, J. Y. Slade, A. E. Oakley and R. N. Kalaria, "Medullary Autonomic Pathology in Carotid Sinus Hypersensitivity," Neuropathology and Applied Neurobiology, Vol. 34, No. 4, 2008, pp. 403-411. doi:10.1111/j.1365-2990.2007.00903.x

[10] P. J. Toorop, M. R. Scheltinga, M. H. Bender, J. A. Charbon, M. C. Huige, F. L. Moll and C. M. Bruijninckx, "Effective Surgical Treatment of the Carotid Sinus Sindrome,” The Journal of Cardiovascular Surgery, Vol. 50, No. 5, 2009, pp. 683-686.

[11] H. H. Trout, L. L. Brown and J. E. Thompson, "Carotid Sinus Syndrome: Treatment by Carotid Sinus Denervation,” Annals of Surgery, Vol. 189, No. 5, 1979, pp. 575580.

[12] R. J. Toorop, M. R. Scheltinga, M. C. Huige and F. L. "Moll, Clinical Results of Carotid Denervation by Adventitial Stripping in Carotid Sinus Syndrome," European Journal of Vascular and Endovascular Surgery, Vol. 39, No. 2, 2010, pp. 146-52. doi:10.1016/j.ejvs.2009.09.009

[13] R. J. Toorop, M. R. Scheltinga and F. L. Moll, “Adventitial Stripping for Carotid Sinus Syndrome," Annals of Vascular Surgery, Vol. 23, No. 4, 2009, pp. 538-547. doi:10.1016/j.avsg.2008.11.008

[14] S. H. Tea, J. Mansourati, G. L’Heveder, D. Mabin and J. J. Blanc, "New Insights into the Pathophysiology of Carotid Sinus Syndrome,” Circulation, Vol. 93, No. 7, 1996, pp. 1411-1416. doi:10.1161/01.CIR.93.7.1411

[15] J. J. Blanc, G. L’Heveder, J. Mansourati, S. H. Tea, P. Guillo and D. Mabin, "Assessment of a Newly Recognized Association: Carotid Sinus Hypersensitivity and Denervation of Sternocleidomastoid Muscles," Circulation, Vol. 95, No. 11, 1997, pp. 2548-2551. doi:10.1161/01.CIR.95.11.2548

[16] A. K. Patel, V. U. Yap, J. Fields and J. H. Thomsen, “Carotid Sinus Syndrome Induced by Malignant Tumours in the Neck: Emergence of Vasodepressor Manifestations Following Pacemaker Therapy,” Archives of Internal Medicine, Vol. 139, No. 11, 1979, pp. 1281-1284. doi:10.1001/archinte.1979.03630480061019

[17] H. R. Muntz and P. G. Smith, "Carotid Sinus Hypersensitivity: A Cause of Syncope in Patients with Tumors of the Head and Neck,” Laryngoscope, Vol. 93, No. 10, 1983, pp. 1290-1293.

[18] A. Sorgente, A. Sarkozy, G. B. Chierchia, C. de Asmundis, L. Capulzini and P. Brugada, "Carotid Sinus Hypersensitivity Following Radiotherapy Delivery in a Patient with Bilateral Glomus Jugular Tumour,” Journal of Cardiovascular Medicine (Hagerstown), Vol. 12, No. 9, 2011, pp. 675-677. doi:10.2459/JCM.0b013e32833a0a2d

[19] M. P. Tan, R. A. Kenny, T. J. Chadwick, S. R. Kerr and S. W. Parry, "Carotid Sinus Hypersensitivity: Disease State or Clinical Sign of Ageing? Insights from a Controlled Study of Autonomic Function in Symptomatic and Asymptomatic Subjects,” Europace, Vol. 12, No. 11, 2010, pp. 1630-1636. doi:10.1093/europace/euq317

[20] C. Finucane, G. Boyle, C. W. Fan, D. Hade, L. Byrne and R. A. Kenny, "Mayer Wave Activity in Vasodepressor Carotid Sinus Hypersensitivity,” Europace, Vol. 12, No. 2, 2010, pp. 247-253. doi:10.1093/europace/eup385

[21] M. P. Tan, J. L. Newton, T. J. Chadwick and S. W. Parry, "The Relationship between Carotid Sinus Hypersensitivity, Orthostatic Hypotension, and Vasovagal Syncope: A Case-Control Study,” Europace, Vol. 10, No. 12, 2008, pp. 1400-1405. doi:10.1093/europace/eun278

[22] A Fedorowski, P Burri, S. Juul-Mo“ller and O. Melander, "A Dedicated Investigation Unit Improves Management of Syncopal Attacks (Syncope Study of Unselected Population in Malmo“-SYSTEMA I),” Europace, Vol. 12, No. 9, 2010, pp. 1322-1328. doi:10.1093/europace/euq168

[23] J. C. Milton, T. C. Lee and S. H. Jackson, "Determinants of a Positive Response to Carotid Sinus Massage and Head-Up Tilt Testing," European Journal of Internal Medicine, Vol. 20, No. 7, 2009, pp. 709-711. doi:10.1016/j.ejim.2009.07.007

[24] R. A. Kenny and G. Traynor, "Carotid Sinus SyndromeClinical Characteristics in Elderly Patients,” Age Ageing, Vol. 20, No. 6, 1991, pp. 449-454. doi:10.1093/ageing/20.6.449

[25] F. P. Sarasin, M. Louis-Simonet, D. Carballo, et al., "Prospective Evaluation of Patients with Syncope: A Population Based Study," American Journal of Medicine, Vol. 111, No. 3, 2001, pp. 177-184. doi:10.1016/S0002-9343(01)00797-5

[26] A. D. McGavigan and S. Hood, “The Influence of Sex and Age on Response to Head-Up Tilt Table Testing in Patients with Recurrent Syncope,” Age Ageing, Vol. 30, No. 4, 2001, pp. 295-298. doi:10.1093/ageing/30.4.295

[27] C. Shibao, C. G. Grijalva, S. Raj, I. Biaggioni and M. R. Griffin, "Orthostatic Hypotension-Related Hospitalizations in the United States," American Journal of Medicine, Vol. 120, No. 11, 2007, pp. 975-980. doi:10.1016/j.amjmed.2007.05.009 